\title{
Analysis of cell cycle-related proteins in mediastinal lymph nodes of patients with N2-NSCLC obtained by EBUS-TBNA: relevance to chemotherapy response
}

\author{
S Mohamed, ${ }^{1,2} \mathrm{~K}$ Yasufuku, ${ }^{1} \mathrm{~T}$ Nakajima, ${ }^{1} \mathrm{~K}$ Hiroshima, ${ }^{3} \mathrm{R}$ Kubo, ${ }^{1}$ A lyoda, ${ }^{1} \mathrm{~S}$ Yoshida, \\ M Suzuki, ${ }^{1}$ Y Sekine, ${ }^{1}$ K Shibuya, ${ }^{1}$ A Farouk, ${ }^{2}$ T Fujisawa'
}

${ }^{1}$ Department of Thoracic Surgery, Graduate School of Medicine, Chiba University, Chiba, Japan; ${ }^{2}$ Department of Pulmonology, Faculty of Medicine, Assiut University, Assiut, Egypt; ${ }^{3}$ Department of Diagnostic Pathology, Graduate School of Medicine, Chiba University, Japan

Correspondence to: Dr K Yasufuku, Department of Thoracic Surgery, Graduate School of Medicine. Chiba University, 1-8-1 Inohana, ChuoKu, Chiba 260-8670, Japan; kyasufuku@faculty.chiba-u.jp

Received 12 September 2007 Accepted 11 March 2008 Published Online First 4 April 2008

\begin{abstract}
Background: Endobronchial ultrasound-guided transbronchial needle aspiration (EBUS-TBNA) is an accurate tool for lymph node staging of non-small cell lung cancer (NSCLC). Most patients with NSCLC require systemic chemotherapy during their treatment, with relatively poor responses. If the response to chemotherapy could be predicted, ideally at the time of the initial bronchoscopic examination, the therapeutic benefit could be maximised while limiting toxicity. A study was therefore undertaken to investigate the feasibility of EBUS-TBNA for obtaining tissue samples from mediastinal lymph nodes that can be used for immunohistochemical analysis, and to stratify patients with molecular-based pN2-NSCLC into chemoresponsive and chemoresistant subgroups who might benefit from tailoring of chemotherapy.
\end{abstract}

Methods: The expression of six cell cycle-related proteins (pRb, cyclin D1, p16 $6^{\mathrm{INK} 4 \mathrm{~A}}, \mathrm{p} 53, \mathrm{p} 21^{\text {Waf1 }}, \mathrm{Ki}-67$ ) in mediastinal lymph node specimens obtained by EBUSTBNA was investigated by immunohistochemistry in 36 patients with pN2-NSCLC. Their predictive role(s) in the response to platinum-based chemotherapy was examined.

Results: Immunostaining was feasible in all studied specimens. Univariate analysis revealed that p53 and p21 Waf1 expressions were significantly related to the response to chemotherapy ( $p=0.002$ and $p=0.011$, respectively). Multivariate logistic regression analysis revealed that only p53 overexpression was associated with a poor response to chemotherapy $(p=0.021)$.

Conclusions: These results suggest that EBUS-TBNA is a feasible tool for obtaining mediastinal nodal tissue samples amenable for immunohistochemical analysis. Immunostaining of p53 in EBUS-TBNA-guided specimens may be useful in predicting the response to chemotherapy in patients with N2-NSCLC and helping in the selection of patients who might benefit from certain chemotherapeutic strategies.

Lung cancer is one of the most common causes of death. While surgery is the standard approach to early stage non-small cell lung cancer (NSCLC), radiotherapy with or without chemotherapy is the main treatment option in locally advanced disease ( $30 \%$ of patients) and chemotherapy remains the only available treatment for those with metastatic disease (50\% of patients). ${ }^{1}$ Moreover, NSCLC is often found to be intrinsically resistant to both chemotherapy and radiotherapy at the start of treatment, but the basis of this resistance to treatment-primary or secondary-remains unknown. ${ }^{2}$ If one could predict the response to chemotherapy based on the assessment of biological tumour markers, one could maximise the therapeutic benefit while limiting toxicity. This assessment would be ideal if performed at the time of the initial bronchoscopic examination so that it would allow patients the option of pursuing alternative regimens earlier in the course of their treatment.

Direct real-time endobronchial ultrasoundguided transbronchial needle aspiration (EBUS TBNA) using the convex probe endobronchial ultrasound is a relatively new minimally invasive and accurate technique for preoperative staging of patients with NSCLC. ${ }^{3-6}$ We have recently reported that EBUS-TBNA has a high sensitivity and specificity compared with computed tomography (CT) and positron emission tomography and, as a single procedure for mediastinal lymph node staging, it allows tissue diagnosis. ${ }^{7}$ Further analysis of tissue samples obtained by EBUS-TBNA such as genetic analysis may help to direct patients with NSCLC to different molecular-based treatments. ${ }^{8}$

Many studies have reported the predictive value(s) of one or more cell cycle proteins for the response to chemotherapy in lung cancer, ${ }^{29}{ }^{10}$ but the results are still controversial. ${ }^{2}$ As patients with stage IIIA N2-NSCLC represent heterogeneous prognostic groups, we examined the expression of the $\mathrm{Rb}$ pathway ( $\mathrm{pRb}$, cyclin $\mathrm{D} 1, \mathrm{p} 16^{\mathrm{INK} 4 \mathrm{~A}}$ ) and $\mathrm{p} 53$ pathway (p53, p21 Waf1) proteins and Ki-67 labelling indices by immunohistochemistry in mediastinal lymph node specimens obtained by EBUS-TBNA from patients with pathologically-proven N2NSCLC and investigated their predictive role(s) for the response to platinum-based chemotherapy. The main objectives of this study were (1) to investigate the feasibility of EBUS-TBNA for obtaining nodal tissue samples that can be used for immunohistochemical analysis and (2) to stratify patients with molecular-based pN2NSCLC into chemoresponsive and chemoresistant subgroups who might benefit from tailored chemotherapy.

\section{METHODS}

\section{Patients and tissue samples}

From July 2004 to April 2006, 67 patients were diagnosed histologically with metastatic lung cancer of the hilar and/or mediastinal lymph nodes in samples obtained by EBUS-TBNA. Rapid on-site cytological examination was conducted for all patients during the procedure. Thirty-six patients in whom analysis of the histological cores revealed 
a pathological diagnosis of stage IIIA N2-NSCLC were enrolled in the study. The presence of both nodal tissue and cancer tissue was confirmed in all specimens by a pathologist. The pathological diagnoses were made according to the World Health Organization classification of lung tumours. ${ }^{11}$ The primary tumour and lymph node status were classified according to the International TNM staging system. ${ }^{12}$ Additional inclusion criteria included (1) no past history of malignancy in the lung or elsewhere in the body; (2) no evidence of distant metastatic disease; and (3) no chemotherapy or radiotherapy before performing EBUS-TBNA. Twenty-eight of the 36 patients received platinum-based combination chemotherapy. The regimens consisted of platinum-based doublets, after which the patients underwent complete post-chemotherapy radiological restaging to evaluate the response to treatment.

\section{EBUS-TBNA}

EBUS-TBNA was performed on an outpatient basis under conscious sedation using a flexible ultrasonic puncture bronchoscope (CP-EBUS, XBF-UC260F-OL8, Olympus, Tokyo, Japan) as described previously. ${ }^{3-578}$ Histological samples were obtained by EBUS-TBNA, as previously reported. ${ }^{578}$ Briefly, a dedicated 22-gauge needle equipped with an internal sheath was used. After the initial puncture the internal sheath was used to clean out the internal lumen clogged with the bronchial tissue. The internal sheath was removed and negative pressure applied by a syringe. The needle was moved backwards and forwards inside the lymph node, after which the needle was retrieved and the internal sheath was used once again to push out the histological core.

\section{Immunohistochemistry}

Immunohistochemical analysis of the specimens was performed to determine the expression of pRb, cyclin D1, p16 $6^{\mathrm{INK} 4 \mathrm{~A}}$, p53 and p21 Waf1 proteins. The Ki-67 labelling index was calculated for Ki-67 expression. All immunohistochemical assays were carried out on $10 \%$ formalin-fixed, paraffin-embedded tissue sections cut to 3-4 $\mu \mathrm{m}$ thickness and mounted on scilanised glass slides (Dako, Glostrup, Denmark). All sections were then dewaxed in xylene, rehydrated through a graded alcohol series and washed in phosphate buffered saline (PBS; $0.01 \mathrm{M}$ sodium phosphate ( $\mathrm{pH} 7.2), 0.15 \mathrm{M} \mathrm{NaCl}$ ). This buffer was used for all subsequent washes and for the dilution of the antibodies. Antigen retrieval was achieved by heating after immersion of the tissue slides in citrate buffer ( $\mathrm{pH}$ 6.0). Tissue sections for cyclin D1, p16 INK4A, p53 and p2 $1^{\text {Waf1 }}$ were heated at $100^{\circ} \mathrm{C}$ five times in a microwave, each for $3 \mathrm{~min}$, while those for Ki-67 and $\mathrm{pRb}$ were heated in an autoclave at $121^{\circ} \mathrm{C}$ for $15 \mathrm{~min}$. All the tissue sections were then processed using the streptavidin-biotin technique (Histofine Kit; Nichirei, Tokyo, Japan). Mouse monoclonal antibodies (Dako, Glostrup, Denmark) specific for cyclin D1 (DSC-6), p53 (DO-7) and Ki-67 (MIB-1) were used at a dilution of 1:40 and 1:800 for cyclin D1 and p53, respectively, and prediluted for Ki-67. Monoclonal antibodies (Santa Cruz Biotechnology, Heidelberg, Germany) and (EMD Biosciences, San Diego, CA, USA) specific for $\mathrm{p} 16^{\text {INK4A }}\left(\mathrm{F}-12\right.$; sc-1661) and $\mathrm{p} 21^{\text {Waf1 }}$ (Ab-1) were used at a dilution of $1: 50$ and $1: 20$, respectively. The monoclonal antibody DO-7 reacts with both wild type and mutant p53 proteins. A rabbit polyclonal antibody (Santa Cruz Biotechnology) specific for $\mathrm{pRb}$ (C-15; sc-50) was used at a dilution of 1:50. All the primary antibodies were incubated overnight at $4^{\circ} \mathrm{C}$. 3,3'-Diaminobenzidine was used as the final chromogen and haematoxylin as the nuclear counterstain.
Positive tissue controls were included in each experiment and consisted of tissues previously shown to stain specifically for the target antigen after exposure to primary antibody.

\section{Evaluation of the immunostaining results}

All slides were evaluated without any knowledge of the clinicopathological features or chemotherapy response of the patients. Two independent observers ( $\mathrm{KH}$ and SM) evaluated the staining pattern of the six proteins separately and scored the protein expression in each specimen by scanning the entire section and estimating the percentage of positive tumour cells. Nuclear colouration was recognised as the primary standard for demonstrating a positive reaction for $\mathrm{pRb}, \mathrm{p} 16^{\mathrm{INK} 4 \mathrm{~A}}, \mathrm{p} 53, \mathrm{p} 21^{\text {Waf1 }}$ and Ki-67, ${ }^{13}{ }^{14}$ irrespective of staining intensity, while for cyclin D1, cytoplasmic staining was recognised as the primary standard for a positive reaction. ${ }^{14}$ A cut-off value of $>10 \%$ tumour cells with positively stained nuclei in the entire section was considered as a positive expression for $\mathrm{pRb}, \mathrm{p} 16^{\mathrm{INK} 4 \mathrm{~A}}$, p53 and $\mathrm{p} 21^{\text {Waf1 }}$, while a cut-off value of $>10 \%$ tumour cells with positive cytoplasmic staining was considered a positive reaction for cyclin D1. ${ }^{14}$ Calculation of the Ki-67 labelling index was performed by counting $>1000$ positively-stained tumour nuclei in randomly selected high-power fields (10-100) from different representative parts of the tumour. Ki-67 labelling indices were defined as high (overexpression) if they were $>20 \%$ and low if they were $<20 \%{ }^{15}$ Abnormal expression was defined as a positive expression of cyclin D1, p53 and high Ki-67 labelling indices and a negative expression (inactivation) of $\mathrm{pRb}, \mathrm{p} 16^{\mathrm{INK} 4 \mathrm{~A}}$ and $\mathrm{p} 21^{\text {Waf1 }}$.

\section{Evaluation of response to chemotherapy}

Patients who received chemotherapy underwent a scheduled CT examination to measure the target tumour size. The responses to chemotherapy were evaluated using Response Evaluation Criteria in Solid Tumors (RECIST) guidelines. ${ }^{16}$ The response rate was defined as the number of chemotherapy responders (complete response + partial response) divided by the total number of patients. The progressive disease rate was defined as the number of patients with progressive disease divided by the total number of patients. ${ }^{16}$ The response to chemotherapy was reviewed without knowledge of the immunostaining results.

\section{Statistical analysis}

The associations between categorical immunohistochemical and clinicopathological parameters and between immunohistochemical parameters and the response to chemotherapy were analysed with the $\chi^{2}$ test or Fisher exact test. The clinicopathological features were age, sex, histopathological type and number of involved mediastinal lymph node stations. To examine simultaneously the impact of more than one factor on the response to chemotherapy, multivariate logistic regression analysis was performed. ${ }^{17}$ Statistical analysis was carried out using the SPSS V.12.0 statistical software program package. The criterion of significance chosen was $p<0.05$ and all tests were two-tailed.

\section{RESULTS}

\section{Patient characteristics and response to chemotherapy}

The clinicopathological features, immunohistochemical results and response to chemotherapy of the patients are shown in table 1 . The response to chemotherapy revealed 1 complete response, 12 partial responses, 10 stable disease and 5 progressive disease. The overall clinical response rate was $46.4 \%$. 
Table 1 Characteristics of 36 patients with pN2-NSCLC

\begin{tabular}{|c|c|}
\hline Characteristic & No (\%) \\
\hline Mean (SD) age (years) & $66.8(9.4)$ \\
\hline$<66.8$ & $14(38.9)$ \\
\hline$>66.8$ & $22(61.1)$ \\
\hline \multicolumn{2}{|l|}{ Sex } \\
\hline Female & $5(13.9)$ \\
\hline Male & $31(86.1)$ \\
\hline \multicolumn{2}{|l|}{ Histopathology } \\
\hline Adenocarcinoma & $19(52.8)$ \\
\hline SCC & $17(47.2)$ \\
\hline \multicolumn{2}{|l|}{ Mediastinal LN stations } \\
\hline Single & $5(13.9)$ \\
\hline Multiple & $31(86.1)$ \\
\hline \multicolumn{2}{|l|}{ Protein expressions } \\
\hline \multicolumn{2}{|l|}{$\mathrm{pRb}$} \\
\hline Negative & $13(36.1)$ \\
\hline Positive & $23(63.9)$ \\
\hline \multicolumn{2}{|l|}{ Cyclin D1 } \\
\hline Negative & $25(69.4)$ \\
\hline Positive & $11(30.6)$ \\
\hline \multicolumn{2}{|l|}{ p16 } \\
\hline Negative & $17(47.2)$ \\
\hline Positive & $19(52.8)$ \\
\hline \multicolumn{2}{|l|}{ p53 } \\
\hline Negative & $17(47.2)$ \\
\hline Positive & $19(52.8)$ \\
\hline \multicolumn{2}{|l|}{ p21 } \\
\hline Negative & $27(75.0)$ \\
\hline Positive & $9(25.0)$ \\
\hline \multicolumn{2}{|l|}{ Ki-67 } \\
\hline LI <20\% & $13(36.1)$ \\
\hline $\mathrm{LI}>20 \%$ & $23(63.9)$ \\
\hline \multicolumn{2}{|c|}{ Treatment response $(\mathrm{n}=28)$} \\
\hline CR & $1(3.5)$ \\
\hline PR & 12 (42.9) \\
\hline SD & $10(35.7)$ \\
\hline PD & $5(17.9)$ \\
\hline
\end{tabular}

$\mathrm{CR}$, complete response; $\mathrm{LN}$, lymph nodes; $\mathrm{LI}$, labelling index; $\mathrm{PD}$, progressive disease; $\mathrm{PR}$, partial response; $\mathrm{SCC}$, squamous cell carcinoma; $\mathrm{SD}$, stable disease.

\section{Immunostaining results}

Remarkably, all the examined cases showed abnormal expression of at least one of the studied cell cycle proteins. The immunostaining results revealed altered expression of $\mathrm{pRb}$, cyclin D1, p16 $6^{\mathrm{INK} 4 \mathrm{~A}}$, p53 and p21 $1^{\mathrm{Waf} 1}$ in $36.1 \%, 30.6 \%, 47.2 \%$, $52.8 \%$ and $75.0 \%$ of nodal biopsies, respectively. With regard to Ki-67, 23/36 cases (63.9\%) had labelling index values $>20 \%$ (table 1). Interestingly, histological cores obtained by EBUSTBNA consisted mainly of tumour cells and blood constituents and minimal amounts of lymph node tissue (fig 1A). Expression of pRb, p16 $6^{\mathrm{INK} 4 \mathrm{~A}}, \mathrm{p} 53, \mathrm{p} 21^{\text {Waf1 }}$ and Ki-67 was present mainly in the nuclei of the tumour cells, whereas cyclin D1 was seen mainly in the cytoplasm (fig 1B). Some cells had additional cytoplasmic (in the case of $\mathrm{pRb}$ ) or nuclear (in the case of cyclin D1) immunostaining.

\section{Relationship between immunohistochemical parameters and clinicopathological features}

We investigated the relationships between the immunohistochemical and clinicopathologic parameters, as well as their possible interrelationship(s). Interestingly, no statistically significant relation was found between the expressions of any two proteins within the $\mathrm{Rb}$ pathway nor between that of p53 and
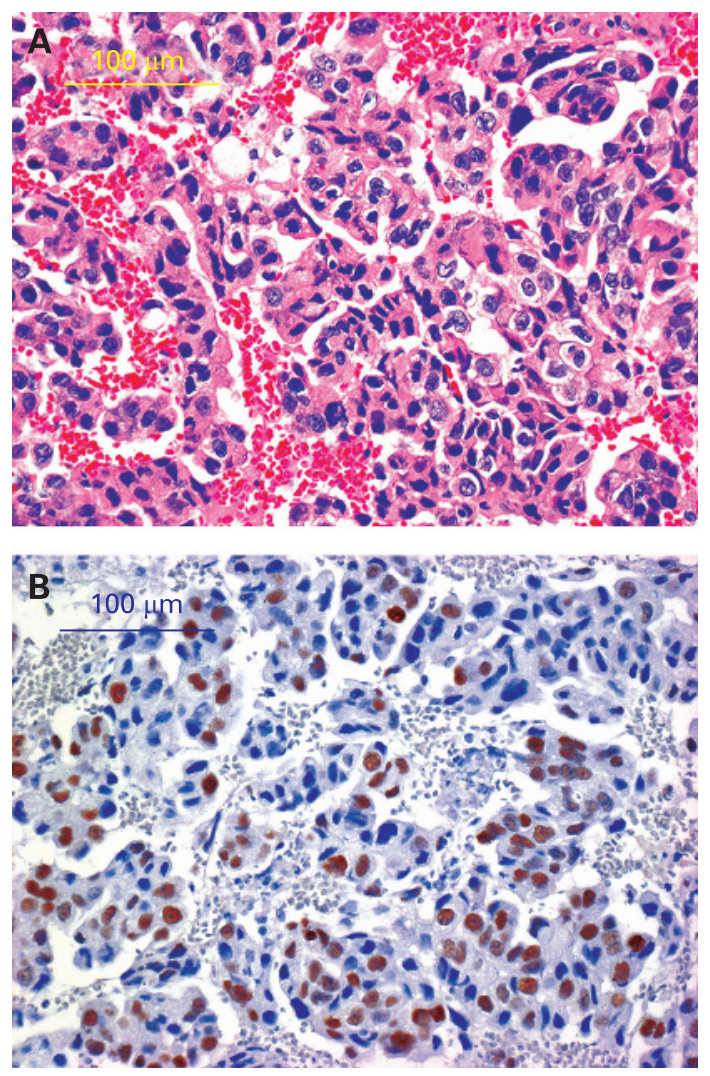

Figure 1 Representative example of mediastinal lymph node tissue sample obtained by endobronchial ultrasound-guided transbronchial needle aspiration (EBUS-TBNA) from a patient with pN2 non-small cell lung cancer (NSCLC) adenocarcinoma (original magnification $\times 20$ ). (A) Note that the main constituents are tumour cells, blood constituents and a small amount of lymphocytes and histiocytes (H\&E).

(B) Immunohistochemical staining for D0-7 showing overexpression of p53 protein.

$\mathrm{p} 21^{\text {Waf1 }}$. Also, no significant relation was found between any two proteins belonging to two different pathways. With regard to the clinicopathological interrelationships, we found that only histopathological type was significantly related to both age and number of involved mediastinal lymph node stations. Significantly more patients with squamous cell carcinoma were older than the mean age of 66.8 years than those with adenocarcinomas (14/22 (63.7\%) vs $8 / 22$ (36.3\%); p =0.013). All 17 patients with squamous cell carcinoma histopathology had multiple mediastinal lymph nodes compared with 14/19 $(73.7 \%)$ of those with adenocarcinoma ( $p=0.047$, data not shown). Some relevant relationships were seen between clinicopathological characteristics and immunohistochemical features (table 2). The sex of the patients was significantly related to $\mathrm{pRb}(\mathrm{p}=0.047)$ and $\mathrm{p} 53(\mathrm{p}=0.047)$ expression; the histopathology was significantly associated with the expression of cyclin D1 $(p=0.042)$ and $p 16^{\text {INK4A }}(p=0.007)$; and the number of involved mediastinal lymph node stations was related to $\mathrm{p} 16^{\mathrm{INK} 4 \mathrm{~A}}$ expression $(\mathrm{p}=0.016)$.

\section{Predictive values for chemotherapy response}

We then analysed the relationship between both the clinicopathological and immunohistochemical parameters and the response to chemotherapy in the 28 patients to whom it was given. None of the clinicopathological parameters was significantly associated with the response to chemotherapy. With 
Table 2 Relationships between immunohistochemical parameters and clinicopathological features

\begin{tabular}{|c|c|c|c|c|c|c|c|c|c|c|c|c|}
\hline \multirow[b]{2}{*}{ IHC parameters $(\%)$} & \multicolumn{2}{|c|}{ Age (years) } & \multirow[b]{2}{*}{ p Value* } & \multicolumn{2}{|c|}{ Sex } & \multirow[b]{2}{*}{ p Value } & \multicolumn{2}{|c|}{ Histopathology } & \multirow[b]{2}{*}{ p Value } & \multicolumn{2}{|c|}{ MLN stations } & \multirow[b]{2}{*}{ p Value } \\
\hline & $<66.8$ & $>66.8$ & & $\mathbf{F}$ & M & & AC & Scc & & Single & Multiple & \\
\hline \multicolumn{13}{|l|}{$\mathrm{pRb}$} \\
\hline Negative (36.1) & 3 & 10 & 0.143 & 4 & 9 & 0.047 & 5 & 8 & 0.196 & 0 & 13 & 0.136 \\
\hline Positive (63.9) & 11 & 12 & & 1 & 22 & & 14 & 9 & & 5 & 18 & \\
\hline Total & 14 & 22 & & 5 & 31 & & 19 & 17 & & 5 & 31 & \\
\hline \multicolumn{13}{|l|}{ Cyclin D1 } \\
\hline Negative (69.4) & 11 & 14 & 0.467 & 3 & 22 & 1.000 & 16 & 9 & 0.042 & 4 & 21 & 0.664 \\
\hline Total & 14 & 22 & & 5 & 31 & & 19 & 17 & & 5 & 31 & \\
\hline \multicolumn{13}{|l|}{ p16 } \\
\hline Negative (47.2) & 9 & 8 & 0.102 & 3 & 14 & 0.650 & 13 & 4 & 0.007 & 5 & 12 & 0.016 \\
\hline Positive (52.8) & 5 & 14 & & 2 & 17 & & 6 & 13 & & 0 & 19 & \\
\hline Total & 14 & 22 & & 5 & 31 & & 19 & 17 & & 5 & 31 & \\
\hline \multicolumn{13}{|l|}{ p53 } \\
\hline \multicolumn{13}{|l|}{ p21 } \\
\hline Negative $(75.0)$ & 11 & 16 & 1.000 & 4 & 23 & 1.000 & 16 & 11 & 0.255 & 4 & 23 & 1.000 \\
\hline Positive (25.0) & 3 & 6 & & 1 & 8 & & 3 & 6 & & 1 & 8 & \\
\hline Total & 14 & 22 & & 5 & 31 & & 19 & 17 & & 5 & 31 & \\
\hline \multicolumn{13}{|l|}{ Ki-67 LI } \\
\hline LI <20\% (36.1) & 4 & 9 & 0.452 & 1 & 12 & 0.634 & 9 & 4 & 0.137 & 1 & 12 & 0.634 \\
\hline $\mathrm{LI}>20 \%(63.9)$ & 10 & 13 & & 4 & 19 & & 10 & 13 & & 4 & 19 & \\
\hline Total & 14 & 22 & & 5 & 31 & & 19 & 17 & & 5 & 31 & \\
\hline
\end{tabular}

$\mathrm{AC}$, adenocarcinoma; F, female; IHC, immunohistochemistry; LI, labelling index; M, male; MLN, mediastinal lymph nodes; SCC, squamous cell carcinoma.

${ }^{*} \chi^{2}$ test or Fisher exact test.

regard to the immunohistochemical parameters, univariate analysis showed that $\mathrm{p} 53$ and $\mathrm{p} 21^{\text {Waf1 }}$ expressions were significantly related to the response to chemotherapy. Twelve of 15 non-responders to chemotherapy had p53 overexpression with response rates of $20 \%$ and $76.9 \%$ for patients with p53positive and p53-negative expression, respectively (estimated risk 0.288, 95\% confidence interval (CI) 0.104 to 0.803 ; $\mathrm{p}=0.002)$. For $\mathrm{p} 21^{\text {Waf1 }}$ expression, $14 / 20$ non-responders had

Table 3 Relationships between the response to chemotherapy and immunohistochemical parameters (univariate analysis)

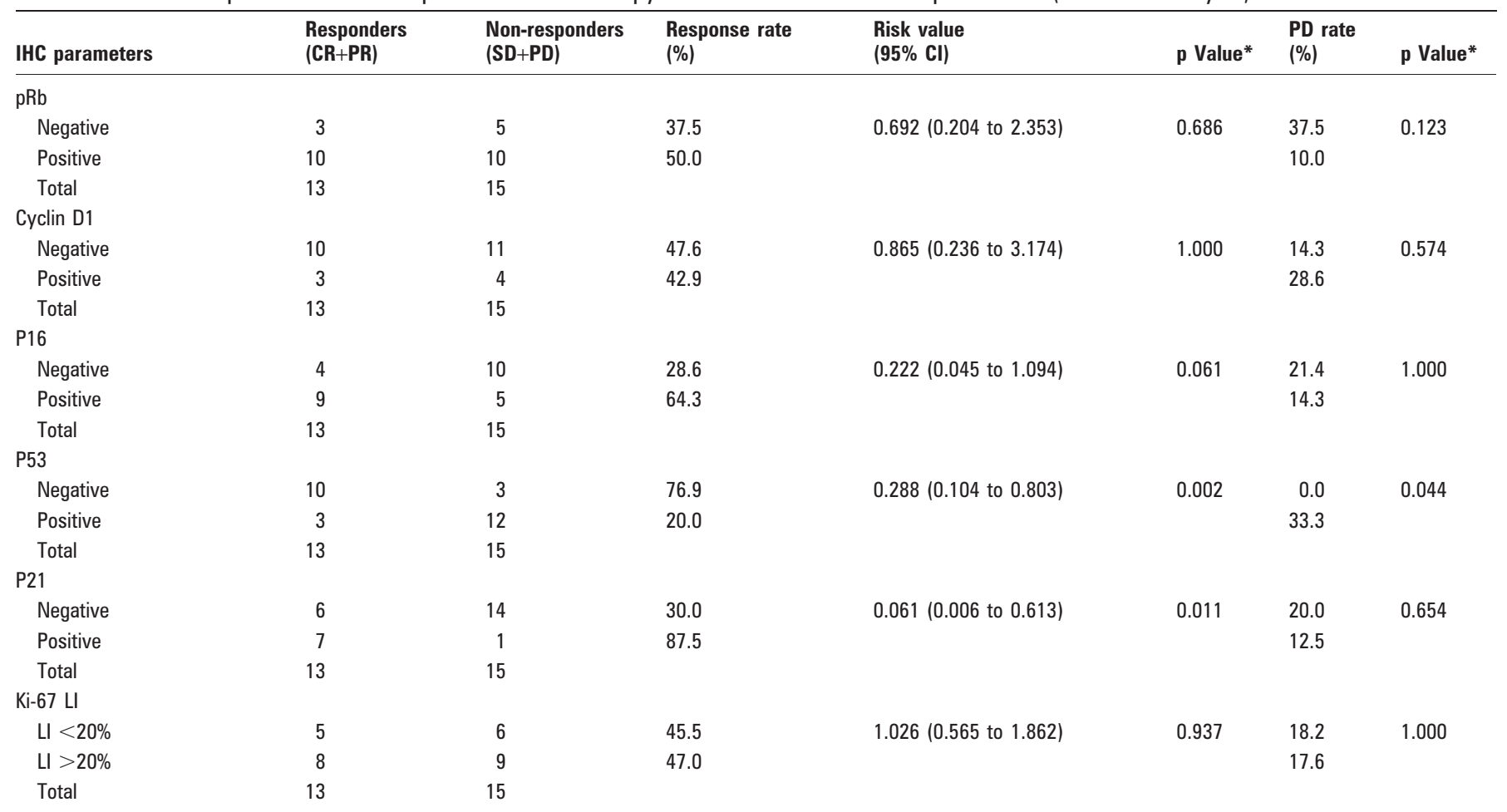

$\mathrm{Cl}$, confidence interval; $\mathrm{CR}$, complete response; IHC, immunohistochemical; LI, labeling index; PD, progressive disease; PR, partial response; SD, stable disease.

${ }^{*} \chi^{2}$ test or Fisher exact test. 
Table 4 Multivariate logistic regression analysis

\begin{tabular}{lll}
\hline $\begin{array}{l}\text { Predictive factors (negative } \\
\text { vs positive expression) }\end{array}$ & 0dds ratio (95\% Cl) & p Value \\
\hline p53 & $0.095(0.013$ to 0.705$)$ & 0.021 \\
p21 & $0.082(0.006$ to 1.056$)$ & 0.055 \\
\hline
\end{tabular}

p21 Waf1 inactivation with response rates of $30 \%$ and $87.5 \%$ for patients with p21-negative and p21-positive expression, respectively (estimated risk $0.061,95 \%$ CI 0.006 to $0.613 ; p=0.011$ ). Moreover, only p53 expression was significantly related to the rate of progressive disease $(p=0.044)$, which is another tool for use in testing the relationship between immunohistochemical parameters and the response to chemotherapy (table 3).

Following the results of the univariate analysis, multivariate logistic regression analysis was performed for the association between $\mathrm{p} 53$ and $\mathrm{p} 21^{\text {Waf1 }}$ expressions and response to chemotherapy (table 4). Only p53 expression was significantly associated with the response to chemotherapy (odds ratio 0.095 , $95 \%$ confidence interval 0.013 to $0.705, p=0.021$ ).

\section{DISCUSSION}

EBUS-TBNA is a relatively new technique for the evaluation of mediastinal and hilar lymph node metastasis in patients with lung cancer. ${ }^{3-7}$ One major advantage of EBUS-TBNA is its ability to collect samples rich in tumour cells which can be confirmed by pathology. ${ }^{57}$ We have recently reported the use of EBUSTBNA for genetic evaluation of tumour cells within the mediastinal lymph nodes of patients with NSCLC. ${ }^{8}$ The use of EBUS-TBNA minimises contamination of non-target normal cells within the samples, which is occasionally seen in transbronchial lung biopsies and/or genetic analyses. ${ }^{8}$ In the current study we obtained relatively small amounts of normal or reactive tissue within the samples compared with the amount of tumour cells. Aberrant expression of at least one of the six cell cycle proteins was found in all the patients studied. Moreover, the percentages of aberrant expressions of these proteins were relatively similar to those published in the literature in which larger population numbers were recruited. ${ }^{13}{ }^{14} 18$ We were also able to establish some statistically significant relationships. The histopathological type was significantly related to age, number of involved mediastinal lymph node stations, and expression of cyclin D1 and p16 $16^{\text {INK4A }}$. Previous reports have shown that different histopathological subtypes of NSCLC may have distinct biological behaviour patterns. ${ }^{19}$ The sex of the patient was related to the expression of $\mathrm{pRb}$ and $\mathrm{p53}$, and the number of lymph node stations was related to $\mathrm{p} 16^{\mathrm{INK} 4 \mathrm{~A}}$ expression. These findings are in agreement with some previously published studies ${ }^{14} 20$ but disagree with others. ${ }^{18}$ This controversy could be explained on the basis of differences between patient populations, sample sizes, methodology and biological heterogeneity of the tumours; ${ }^{18}$ the latter is particularly a characteristic feature of pN2-NSCLC. ${ }^{14}$ Our results showed a lack of significant interrelationships between cell cycle markers which has also been observed by others. ${ }^{14}{ }^{18}$

Given the low response rates to chemotherapy and the high incidence of side effects, the use of molecular marker(s) in patients with NSCLC to determine whether tumours may be resistant to a particular treatment regimen would avoid unnecessary toxicity and reduce medical costs. This assessment would ideally be performed at the time of the initial bronchoscopic examination so that it would allow a better selection of patients who may benefit from specific neoadjuvant or adjuvant chemotherapy regimens. Our results showed that only p53 expression was significantly related to the response to chemotherapy. The expression of p53 is normally not detectable by immunohistochemistry. However, the mutant p53 proteins have an extended half-life so they accumulate in tumour cells and result in the apparent overexpression of p53 on immunohistochemical examination. ${ }^{21}$ Radiotherapy and most chemotherapeutic agents directly target $\mathrm{DNA}^{2}$ and, in response to such therapies, p53 functions as a coordinator of the DNA repair process, cell cycle arrest and apoptosis. ${ }^{22}$ Notably, p53 participates in the main DNA repair systems operative in cells (reviewed by Viktorsson et $a l^{2}$ ). Given the high frequency of p53 mutations in lung cancer, a role for p53 as a predictive marker for the response to treatment has been strongly suggested. In response to DNA damage at least some of the p53 mutants show less capacity to bind and initiate transcription from their target genes (eg, p21 WAF1,$M d m 2$, Bax, cyclin $G$ ), so some of the p53-mediated effects are blunted. ${ }^{23}$ Several bodies of evidence have linked p53 with the response to treatment, observing that most chemotherapeutic agents were more effective in killing human tumours with wild type rather than mutant p53. ${ }^{24} 25$ Indeed, given the important function of nucleotide excision repair in the repair of DNA damage induced by platinum-based chemotherapy, it has been shown that increased nucleotide excision repair activity in NSCLC cell lines or tumours is associated with increased failure in the response to chemotherapy. ${ }^{26}$ Furthermore, resistance to cisplatin was associated with increased activity of excision repair crosscomplementing group 1 (ERCC1) and, notably, this polymorphism was measurable at the mRNA level and thus could act as a predictive marker for the outcome to treatment. ${ }^{27}$ Our results support the role of p53 as overexpression of p53 was associated with a poor response to platinum-based chemotherapy.

With regard to our previous work, ${ }^{14}$ the discrepancy between survival and the response to chemotherapy can be explained in two ways. First, the presence of aggressive tumour features and the resulting shortened survival time does not necessarily lead to treatment resistance because, on the one hand, chemotherapy and radiotherapy may target different pathways and, on the other, a shorter survival time is not always linked to treatment resistance. ${ }^{2}$ Second, there may be differences in protein expression between primary and metastatic sites. Primary and metastatic tumour cells may exhibit different characteristics and the former cells may undergo selection in the course of metastasis. ${ }^{28}$ On the other hand, conserved mutations have been observed between primary and metastatic sites. ${ }^{29}$

Our results could have important clinical and therapeutic implications. Being a minimally invasive procedure that can be done repeatedly under local anaesthesia, EBUS-TBNA represents a very useful tool for the initial assessment and follow-up of patients with N2-NSCLC. It can help to identify patients who may benefit from induction chemotherapy or adjuvant chemoradiotherapy $^{30}$ and those for whom surgery may be beneficial. Furthermore, EBUS-TBNA may become a useful tool for molecular assessment following induction chemotherapy that may help to direct patients to different therapeutic strategies. ${ }^{81}$ From the therapeutic point of view, recent studies have used manipulations to mutant p53-either functional correction or elimination-to improve existing treatments or even to highlight new anticancer strategies..$^{32}$

Our study has two possible limitations-the relatively small number of patients and the fact that it is a retrospective study. Further larger prospective studies evaluating molecular markers in EBUS-TBNA-guided biopsies are therefore needed. 
In conclusion, the results of this study suggest that EBUSTBNA is a feasible tool for obtaining mediastinal nodal tissue samples amenable for immunohistochemical analysis. Immunostaining of p53 in specimens obtained by EBUSTBNA may be useful in predicting the response to chemotherapy in patients with N2-NSCLC which may lead to a better selection of patients who might benefit from certain chemotherapeutic strategies.

Acknowledgements: The authors thank Professor Hammad El-Shahhat and Dr Gamal Agamy of the Department of Pulmonology and Dr Eman Mahmoud of the Department of Pathology, Assiut University for their help with this work.

Funding: KY received Grants-in-Aid for Scientific Research from the Ministry of Education, Culture, Sports, Science and Technology of Japan Nos 16591384 and 19591611.

Competing interests: None.

Ethics approval: This study was approved by Chiba University Institutional Review Board (approval No. 119).

\section{REFERENCES}

1. Spira A, Ettinger DS. Multidisciplinary management of lung cancer. $N$ Engl J Med 2004:350:379-92.

2. Viktorsson K, De Petris L, Lewensohn R. The role of p53 in treatment responses of lung cancer. Biochem Biophys Res Commun 2005;331:868-80.

3. Yasufuku K, Chhajed PN, Sekine Y, et al. Endobronchial ultrasound using a new convex probe: a preliminary study on surgically resected specimens. Oncol Rep 2004;11:293-6.

4. Yasufuku K, Chiyo M, Sekine $\mathrm{Y}$, et al. Real-time endobronchial ultrasound-guided transbronchial needle aspiration of mediastinal and hilar lymph nodes. Chest 2004;126:122-8

5. Yasufuku K, Chiyo M, Koh E, et al. Endobronchial ultrasound guided transbronchial needle aspiration for staging of lung cancer. Lung Cancer 2005;50:347-54.

6. Herth FJ, Eberhardt R, Vilmann $P$, et al. Real-time endobronchial ultrasound guided transbronchial needle aspiration for sampling mediastinal lymph nodes. Thorax 2006;61:795-8.

7. Yasufuku K, Nakajima T, Motoori K, et al. Comparison of endobronchial ultrasound, positron emission tomography, and CT for lymph node staging of lung cancer. Chest 2006;130:710-8.

8. Nakajima T, Yasufuku K, Suzuki M, et al. Assessment of epidermal growth factor receptor mutation by endobronchial ultrasound-guided transbronchial needle aspiration. Chest 2007:132:597-602.

9. Harada T, Ogura S, Yamazaki K, et al. Predictive value of expression of P53, Bcl-2 and lung resistance-related protein for response to chemotherapy in non-small cell lung cancers. Cancer Sci 2003;94:394-9.

10. Gautschi 0, Hugli B, Ziegler A, et al. Cyclin D1 (CCND1) A870G gene polymorphism modulates smoking-induced lung cancer risk and response to platinum-based chemotherapy in non-small cell lung cancer (NSCLC) patients. Lung Cancer 2006;51:303-11.

11. Travis WD, Brambilla E, Müller-Hermelink HK, et al. World Health Organization Classification of Tumours. Pathology and genetics. Tumours of the lung, pleura, thymus and heart. 4th ed. Lyon: IARC Press, 2004:10.
12. Mountain CF, Dresler CM. Regional lymph node classification for lung cancer staging. Chest 1997;111:1718-23.

13. Burke L, Flieder DB, Guinee DG, et al. Prognostic implications of molecular and immunohistochemical profiles of the $\mathrm{Rb}$ and $\mathrm{p} 53$ cell cycle regulatory pathways in primary non-small cell lung carcinoma. Clin Cancer Res 2005;11:232-41.

14. Mohamed S, Yasufuku K, Hiroshima K, et al. Prognostic implications of cell cyclerelated proteins in primary resectable pathologic N2 nonsmall cell lung cancer. Cance 2007; 109:2506-14.

15. Shiba M, Kohno $\mathrm{H}$, Kakizawa $\mathrm{K}$, et al. Ki-67 immunostaining and other prognostic factors including tobacco smoking in patients with resected non-small cell lung carcinoma. Cancer 2000;89:1457-65.

16. Therasse $\mathbf{P}$, Arbuck SG, Eisenhauer EA, et al. New guidelines to evaluate the response to treatment in solid tumors. J Natl Cancer Inst 2000;92:205-16.

17. Cox DR, Snell EJ. Analysis of binary data. 2nd ed. London: Chapman and Hall, 1989

18. Geradts J, Fong KM, Zimmerman PV, et al. Correlation of abnormal RB, p16ink4a, and p53 expression with 3p loss of heterozygosity, other genetic abnormalities, and clinical features in 103 primary non-small cell lung cancers. Clin Cancer Res 1999:5:791-800.

19. Mangili F, Cigala C, Arrigoni G, et al. Cell loss and proliferation in non-small cell lung carcinoma: correlation with histological subtype. Eur J Histochem 1998;42:287-95.

20. Esposito V, Baldi A, Tonini $G$, et al. Analysis of cell cycle regulator proteins in nonsmall cell lung cancer. J Clin Pathol 2004;57:58-63.

21. Tominaga $\mathbf{0}$, Hamelin $R$, Remvikos $Y$, et al. p53 from basic research to clinical applications. Crit Rev Oncog 1992:3:257-82.

22. El-Deiry. The role of p53 in chemosensitivity and radiosensitivity. Oncogene 2003:22:7486-95.

23. de Vries A, Flores ER, Miranda B, et al. Targeted point mutations of p53 lead to dominant-negative inhibition of wild-type p53 function. Proc Natl Acad Sci USA 2002;99:2948-53.

24. O'Connor PM, Jackman J, Bae I, et al. Characterization of the p53 tumor suppressor pathway in cell lines of the National Cancer Institute anticancer drug screen and correlations with the growth-inhibitory potency of 123 anticancer agents. Cancer Res 1997; 57:4285-300.

25. Schmitt CA, Fridman JS, Yang M, et al. A senescence program controlled by p53 and p16INK4a contributes to the outcome of cancer therapy. Cell 2002;109:335-46.

26. Tsai CM, Chang KT, Li L, et al. Interrelationships between cellular nucleotide excision repair, cisplatin cytotoxicity, HER-2/neu gene expression, and epidermal growth factor receptor level in non-small cell lung cancer cells. Jpn J Cancer Res 2000;91:213-22.

27. Isla D, Sarries C, Rosell R, et al. Single nucleotide polymorphisms and outcome in docetaxel-cisplatin-treated advanced non-small-cell lung cancer. Ann Oncol 2004:15:1194-203.

28. Okamoto A, Hussain SP, Hagiwara K, et al. Mutations in the p16INK4/MTS1/CDKN2, p15INK4B/MTS2, and p18 genes in primary and metastatic lung cancer. Cancer Res 1995:55:1448-51.

29. Schlegel U, Rosenfeld MR, Volkenandt M, et al. p53 gene mutations in primary lung tumors are conserved in brain metastases. J Neurooncol 1992;14:93-100.

30. Bepler G. Using translational research to tailor the use of chemotherapy in the treatment of NSCLC. Lung Cancer 2005; 50(Suppl 1):P13.

31. Goldstraw $\mathbf{P}$. Selection of patients for surgery after induction chemotherapy for N2 non-small-cell lung cancer (editorial). J Clin Oncol 2006;24:3317-8.

32. Bykov VJ, Issaeva N, Shilov A, et al. Restoration of the tumor suppressor function to mutant p53 by a low-molecular-weight compound. Nat Med 2002;8:282-8.

33. Fujiwara T, Tanaka N, Kanazawa S, et al. Multicenter phase I study of repeated intratumoral delivery of adenoviral p53 in patients with advanced non-small-cell lung cancer. J Clin Oncol 2006;24:1689-99. 